\title{
Magnesium L-threonate
}

National Cancer Institute

\section{Source}

National Cancer Institute. Magnesium L-threonate. NCI Thesaurus. Code C123781.

A nutritional supplement containing the L-threonate form of magnesium $(\mathrm{Mg}$ ) that can be used to normalize Mg levels in the body. Upon administration, Mg is utilized by the body for many biochemical functions and reactions including: bone and muscle function, protein and fatty acid formation, activation of B vitamins, blood clotting, insulin secretion, and ATP formation. Mg also serves as a catalyst for many enzymes throughout the body. In addition, magnesium improves the functioning of the immune system by enhancing the expression of natural killer activating receptor NKG2D in cytotoxic Tlymphocytes and natural killer (NK) cells. This increases their anti-viral and anti-tumor cytotoxic effects. 